\title{
How Big Data Collected Via Point of Sale Devices in Textile Stores in Spain Resulted in Effective Online Advertising Targeting
}

\author{
https://doi.org/10.3991/ijim.v14i13.14359 \\ Gloria Jiménez-Marín, Paloma Sanz-Marcos \\ University of Seville, Seville, Spain \\ Irene García Medina $(\bowtie)$ \\ Glasgow Caledonian University, Glasgow, Scotland \\ irene.garcia2@gcu.ac.uk \\ Patrícia Margarida Farias Coelho \\ Methodist University of São Paulo, São Bernardo do Campo, Brazil
}

\begin{abstract}
In these days of online commerce, we need to know the real behavior of consumers in physical stores: the points of sale must anticipate the purchasing decisions of consumers in order to be able to offer the best buying experience as well as tailor the marketing variables to the specific needs of each consumer. This is where retail intelligence emerges, especially in the textile industry, as a potential technology that makes use of extremely large data sets ("big data") to engage potential customers better in order to increase company sales. The objective of this study is to show how big data can be effectively leveraged for direct and clear commercial purposes in textile stores. The development of research is based on the analysis of the application of systematic observation of consumer behavior in three main streets in Spain known for textile retail stores and interpreting their differences. The results show that data collected through various point-of-sale devices have a significant influence on retail revenue. The differences between commercial areas and the relative attractiveness of the textile trade in different cities are also borne out by the results. The main conclusions point to the need to improve the profitability of textile fashion stores on the back of promotional tactics that focus on the number of estimated customers and the possibilities of selling to them. All of the aforesaid have a significant influence on how advertising planning is carried out for retail stores.
\end{abstract}

Keywords - Advertising, big data, communication, textile, retail, smart data.

\section{Introduction}

The economic recession has been devastating Spain since 2008, with GDP plunging $3.1 \%$ in 2009 and unemployment rates of more than $20 \%$. The 2009 fiscal closed on a 
grim note; physical stores posted a $12 \%$ slump in sales and the number of premises shrunk by a whopping 40,000 while 90,000 people were rendered jobless [1].

In such a gloomy scenario, would people visit any textile store at all and even if they do visit, what are they most likely to shop? These questions piqued our curiosity as researchers. It is true that there were a large number of companies that sold shop-per counting solutions. Typically, most such solutions comprised of infrared devices installed on one side of the store's entrance and projected a horizontal beam of infra-red light across the entrance. When a shopper walked past the beam, there was a "break" in the beam of light, and every such break was recorded by the device as a single customer. They were two such devices - one at the entrance, the other, at the exit, and the final count of shoppers was obtained by merging data from both sources [2]. In addition, the cash tickets were counted to get a ballpark count of shoppers.

The people counting system, which is the subject matter of this research, was Retail Intelligence ${ }^{\circledR}$ from Barcelona-headquartered TC Group Solutions, a reputed provider of technology offerings that enable the collection and analysis of extremely large data sets ("big data") from within and outside commercial establishments. Apart from capturing data on entries and exits, this system records data on the duration of stay of potential customers, hourly distribution of customers on a certain day, the number of customers who pass in front of a point of sale as well as the number of passersby who pause to gaze at goods in the shop window. Such granular data helps in refining and retargeting the store's customer communication as well as delivering a more personalized experience for the customer. The key idea is to derive valuable insights from the torrent of data captured by the people counting system and make the most of it in terms of improved sales, profits, and customer retention.

\subsection{Theoretical framework}

Smart Data: According to the annual study of social networks (2018) by the Interactive Advertising Bureau, Spain [3], a trade group responsible for developing technical standards and best practices for media and digital marketing industries, in just one minute:

- 66,000 images are uploaded on Instagram

- 500 hours of video are uploaded on YouTube

- 3.3 million publications appear on Facebook

- 3.8 million searches happen on Google

- 29 million messages are sent via WhatsApp

During 2016 Black Friday (Friday 25th), Amazon posted new record sales in Spain: almost one million products sold, specifically 940,000 units in 24 hours, which works out to just over 10 products per second. In the process, the ecommerce giant almost doubled its own previous record sale of 570,000 units.

Amazon was not the only one to rake in high revenues. Just 15 days earlier, Chinese e-commerce major Alibaba also broke all of its previous sales records in the so-called Singles' Day, hitting more than 91,200 million yuan (13,390 million euros) in a little 
more than 15 hours, Asenador [4] wrote in the Spanish business newspaper Expansión. In just 6 minutes and 58 seconds, the Chinese conglomerate invoiced more than 10,000 million yuan (1,349 million euros); and in 1 hour and 11 minutes from the start of the 'Singles' Day,' it clocked 36,200 million yuan (4,882 million euros) of sales via mobile devices. At the end of 14 hours and 33 minutes, Alibaba had generated 467 million orders. Contemporary high-performance technology has placed before decision makers at enterprises a disproportionately huge mass of data, characterized not only by its Volume, but also by the Velocity at which it is processed, as well as Variety of media, formats and fonts - (the three 'V's), observes Jiménez-Marín [5].

Specialized companies apply complex precision tools on enterprise data, "pulling it together," representing it graphically, ensuring it fits the specific needs of a certain business (usability), and making relevant data accessible in real time for decision makers on an as-needed basis. These specialty data service providers have the responsibility of contributing the fourth " $\mathrm{V}$ " to the big data, what Kalinin et al. [6] refer to as "generation of Value."

Given that data is of little use to a business if it fails to generate value for its users, it is necessary to identify the kind of data that is really relevant for the store under consideration. Essentially, such data must answer the key question about whether or not the managerial actions or decisions taken at the store were effective in terms of store performance. In short, data that represents the achievement of each key performance indicator (KPI1) as a measurable value is the one that is relevant. In this sense, and following Gungor et al. [7], amidst the tsunami of big data flooding our businesses, smart data are those that provide relevant, accurate, and timely information for each KPI of a business. And for this reason, it's the collection, storage, processing, and analysis of KPI-related data using appropriate retail intelligence tools that we need to worry about most.

\subsection{Retail intelligence indicators}

They are the performance measures of all companies and indicates whether or not something is working or some strategy or tactic is working better than expected. Based on this, the strategy or tactic, for instance, can be replicated, and, above all, even where an enterprise is doing exceedingly well, carrying out performance evaluations from time to time will ensure the business doesn't end up as a victim of its own success.

In this sense, and following Fernandez [2], the evaluation of the way a business is managed almost always means starting from a certain set of performance indicators or results. No matter if these measures are labelled as KPIs or KRIs (Key Results Indicators), in their essence, they are a set of specific metrics that each business uses to quantify the achievement of those objectives that reflect the performance or results of the organization as a whole for a certain time frame.

When evaluating the management of physical stores, four basic indicators have almost always been mentioned: total sales values, average sales values per customer (or average ticket amount), sales per seller, and sales per square meter. These data, though

${ }^{1}$ Key Performance Indicators (KPIs) are metrics used to quantify results. 
absolutely useful and necessary, reflect sales closures, which is only a part of the reality of store performance. They are, therefore, KRIs or performance indicators of the store's financial position, i.e., financial metrics. The most common characteristic of KRIs is that they represent a summation of several actions and give us a clear picture of whether the company is on the right path and it is achieving the strategic objectives sought to be achieved. Even so, KRIs do not help decision makers to go the extra mile to communicate to staff or managers what they should do to correct and/or improve upon those actions. A narrow focus on the indicators of results might lead us to draw biased and, worse still, wrong conclusions.

KPI, as different from KRI, keeps in focus each one of the actions of the general strategy and directly influences its development and fulfillment. A KPI analyses a single link in the result chain, and each link has a critical effect on most of the other links or remaining metrics, and, furthermore, promotes positive and corrective actions capable of affecting the entire result chain.

At this juncture, we feel it's worthwhile to present a third and basic concept: Customer Conversion Rate (CCR), which is a measure of the percentage of visitors to a store who make a purchase. Conversely, the ratio tells us how many visitors have left the store empty-handed, certainly a very important piece of data if you are looking to take full advantage from the potential of each point of sale.

By quantifying the percentage of potential customers who have left the store without buying, this ratio proves handy when it comes to evaluating the effectiveness of the sales team and staff. The conversion ratio is also indicative of other essential aspects of the store since it records the observation before and after a certain change or modification is made at the store and matches the store metrics against some desired result. Store aspects in this respect would include the attractiveness or otherwise of the store's customer offers, floor space, and product display.

There is a fourth element as well, namely, attraction ratio or conversion rate of inputs, based on the number of potential customers among people who flock past each business. The visitor conversion rate (VCR), is the result obtained by dividing the number of people entering a store by the pedestrian traffic in front of a store. Among other things, VCR can provide responses to business queries like - Are the store windows attractive enough? What days or hours of the week are people most likely to enter the store?

Pedestrian traffic offers the absolute value of the number of people who spend time in a certain part of a shopping street in a certain year, month, day or even an hour. The average number of passers-by is key to estimating the volume of potential customers for a commercial establishment. Because a thorough analysis of this ratio would enable managers to make better decisions around customer offers, visual merchandising, store staff, and even in terms of the valuation and negotiation of rentals of their commercial premises.

We add one last element here: The cost per potential customer (CCP), which is the result of combining the number of people or potential customers who spend each month in front of a store with the monthly cost of renting the premises. In this measure, each potential customer who passes in front of a point of sale is assigned a monetary value in euros. 
This metric helps to manage the profitability of the commercial premises by serving as a conditioner in the closing of some rental contracts and as a justification in subsequent negotiations. In other words, when a retailer plans to expand outside its known area (usually its city or country of origin), it is necessary to gather objective data on pedestrian traffic in order to identify the busiest streets and ones that show the potential to provide a more profitable CCP.

\subsection{Big data and advertising}

Advertising is a field that is in a state of constant transformation and forever struggling to adapt to social and technological changes in its environment [18]. The digital change has been driving transformations to the logic underpinning advertising as a discipline, as pointed out by Feijóo González, Gómez Barroso and Martínez-Martínez [8]. In an environment marked by proliferation of virtual communication channels and an equally considerable capacity for segmentation, the challenge before marketers' spreads across three dominant variables: price, scale, and efficiency. As in the case of many other domains in this connected world, automation is the natural and immediate response from businesses to this type of challenge [9]. And that automation is where programmatic advertising comes in.

Given the current scenario where it is very difficult to say for sure what exactly is a communication channel and what is not programmatic advertising has been configured as a solution to this uncertainty [10]. Programmatic advertising (also referred to as "programmatic purchasing") is digital advertising that is based on purchase and planning processes and employs various algorithms and software to this end. According to IAB's White Paper [11], "programmatic advertising simplifies the exchange process [involving cash or cash equivalent for goods and services] by adding operational efficiency through the digital connection of buyer and seller, and making it possible to programmatic purchase of advertisements through marketing platforms." Not only does this genre of advertising harness algorithms to process the sale of prints (thus redefining the figure of the planner), but it also automates key aspects of advertising such as segmentation, profile systematization, and inventory management. In this sense, effective use of data is a hallmark of programmatic advertising and this makes it possible to optimize both pre-campaign planning and post-campaign seg-mentation and analysis.

Martínez-Martínez, Aguado and Boeykens [12] hold the view that the process of programmatic advertising begins when a user connects to a specific website, has an active app, or has her/his location activated on the mobile phone. Where one of these three circumstances is satisfied, there is an exchange of information, voluntary or involuntary, between advertisers and users. Still again, it depends on whether the subject of the study is an online customer or an offline one. The various information exchange platforms operate as exchange points for other platforms, such as de-mand-side platforms (DSP) and advertising networks. These can not only provide additional information about the user but they can also make buyers available. This is where usage of big data becomes especially relevant to the process of advertising as it helps to train the focus on a direct purchase objective. 
According to several reports on investment in programmatic advertising [11] [3], most advertisers use a direct programmatic through the real-time bidding (RTB) system. Users' profile and behavioral data are the main assets at both ends of this exchange process (Figure 1).

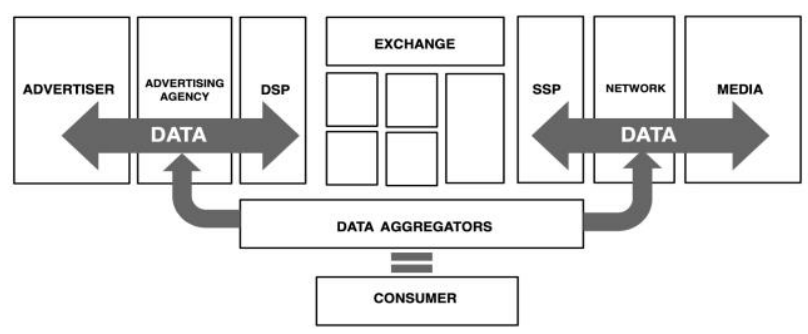

Fig. 1. Programmatic advertising ecosystem

Source: [12]

While programmatic advertising is very well established in markets like the US, it is still playing catch-up in countries like Spain, for instance. In 2015, purchase of programmatic advertising in the US exceeded 10,000 million dollars versus 9,400 million dollars in conventional advertising [13];Meanwhile in Spain, in 2016, out of a total of 259.6 million euros of advertising investment in digital formats and/or digital media, programmatic purchases attracted only 36.9 million euros [3]. Despite that, the average annual growth rate for the 2016 first half showed a $25.6 \%$ increase for programmatic advertising [3].

To illustrate this question, we present a real case: FNAC, a megastore selling CDs, DVDs, video games, electronic equipment and books in Seville, Southern Spain (2017). According to the company's own sources, the use of programmatic advertising, thanks to the data on "active location setting" on customers' mobile phones, accounted for up to $30 \%$ increase in real purchases made at the point of sale (POS).

Along the same lines, Madrid-based media agency Infoadex's study of advertising spend $(2019$, p. 4), says advertising in non-conventional media touched $57.1 \%$ in 2018 , with $31.6 \%$ of the total for advertising in digital media.

\section{$1.4 \quad$ Objectives}

The objectives of this study are to:

- Highlight the importance of big data in commerce and advertising.

- Demonstrate the increase in the number of potential buyers entering commercial establishments as a result of meeting KPIs.

- Increase the profitability of commercial establishments making use of location as an advertising tool.

González (1997) is of the view that observation is one of the procedures that allows collection of such data. 


\section{Methodology}

In the eyes of González [14], observation is about systematically and carefully contemplating how social life develops. She alludes to a set of methods laid down for the direct observation of events that occur in a natural way. This definition brings in two main considerations: firstly, that the data is collected when the event occurs; however, this does not, in any way, preclude the possibility of recording or other means of collecting this data for later analysis; secondly, it means that the event is not staged, created, maintained or finished exclusively for the benefit of the research. (A little later in this narrative, we will be talking about the so-called experimental method [14]).

According to González, observation is the most important research technique used in sociology so much so that "no other technique can replace the direct contact of the researcher with the field of study" [14]. In the specific scope of the present research, the observation technique is used both in the phase prior to the selection and formulation of the problem that is going to be the subject matter of our investigation, as well as in the data collection phase.

The observation technique falls into two distinct types: systematic observation and participant observation. Systematic observation is the monitoring and recording of previously specified behaviors and actions [14]). It can be applied as long as the setting selected is a public one and allows the researcher to make the observation without being a direct participant in the scenario. However, when it comes to participating observation, unlike in systematic observation, the researcher is a part of the events observed.

Given the specifics of our case, we resorted to intervened systematic observation, wherein we use the previously defined indicators in both an exploratory and descriptive manner. Based on this as also the Big Data Report on Consumer Behaviour [15] in Spanish shopping streets, we analyze the differences between the distribution of pedestrian traffic in three main streets in the Spanish cities of Madrid, Barcelona, and Seville: Gran Vía in Madrid; Barcelona's Passeig de Gràcia and Tetuán; and Velázquez streets in Seville. The rationale behind their selection was that these were the cities that saw the highest commercial traffic in 2018, as per the Spain Report by Point-of-Purchase Advertising International (POPAI), an industry organization dedicated to promoting instore excellence. Our data was gathered both during a shopping day and for an entire week for all three cities in December 2018.

\section{$3 \quad$ Results}

\subsection{Cost per customer}

By knowing the number of potential customers who pass in front of the window of a textile store or point of sale, it should be possible to control other indicators such as the cost per potential customer (CPC). To this extent, the possibilities before retail intelligence, in terms of data analysis, are unlimited.

The data collected during December 2018 from in-store people-counting devices reveals: 
- Barcelona's Passeig de Gràcia has a daily average of 25,135 pedestrians and a rental price for its commercial premises of 257 eur $/ \mathrm{m} 2 / \mathrm{month}$.

- Madrid's Gran Vía, 29,129 pedestrians daily and a rental of $242 \mathrm{eur} / \mathrm{m} 2 / \mathrm{month}$.

- The adjoining streets of Tetuán and Velázquez in Seville have a daily average of 21,817 and a rental of 145 eur/m2/month.

The PCC calculation will indicate that a $100 \mathrm{~m} 2$ premises in any of these streets will likely generate, in respect of each potential customer, on average euro cents of 0.83 in Madrid's Gran Vía, 0.82 in Barcelona's Passeig de Gràcia, and 0.66 in Seville.

Table 1. Traffic estimates (CP) in different areas and cities.

\begin{tabular}{|l|l|c|c|}
\hline \multicolumn{1}{|c|}{ City } & \multicolumn{1}{c|}{ Street } & Estimated daily traffic (CP) & Marketing $€ /$ month/m2 \\
\hline Madrid & Gran Vía & 29,129 & 242 \\
\hline Barcelona & Passeig de Gràcia & 25,135 & 257 \\
\hline Seville & Tetuán/Velázquez & 21,187 & 145 \\
\hline
\end{tabular}

Source: Own elaboration

A person might be on a certain road at a certain time of day for umpteen reasons: it can be a passing street, or the access to a site; there could be a public transport stop nearby, or probably a school, and so on. But from our research standpoint, the only matter relevant to us is the purchase intent of people on a street at any given point of time. On a given day, suppose there are 10,000 pedestrians on a particular street and the average attraction ratio of the shops in the street is, say, $8 \%$. This works out to an average of 800 customers with an intent to buy. Another street can have a daily average of 6,000 pedestrians and a $12 \%$ attraction rate, which means 720 average leads.

By knowing the percentage of pedestrians who have passed in front of a point of sale and, for some reason, have been attracted to walk into the store, a store manager can understand which showcase or what campaign has generated a greater number of leads, in which case, she/he can replicate the tactic on other occasions and even in other stores belonging to the same retail chain. This action will increase the attraction ratio and, in turn, lead to a proportional increase in sales.

In this context, we turn to big data and its potential to help us gauge the behavior of different cities, areas, and shopping streets that are at the focus of our study. The metrics we are trying to derive, with respect to these locations, include their pedestrian flow, the days and hours of more and less affluence, the impact on the customer's readiness to purchase, and the cost per potential client derived from the real estate rental price. As per the Big Data Report on Consumer Behavior, the shopping streets of Madrid, Barcelona and Seville in 2017 registered an average global attraction ratio of $9.75 \%$, $8.97 \%$ and $7.99 \%$ respectively. If we further drill down to stats on the fashion sector, the purchase intent of passers-by is around $8.35 \%$ in Madrid, $8.85 \%$ in Barcelona, and $8.72 \%$ in Seville. A store's score, be it above or below this average, is an indication to the retailer of the level of attractiveness and effectiveness of each point of sale, shop window, or advertising campaign.

The first step for a retailer is to get the potential customer to the point of sale; the next step is to "convert" these visitors who have already been wooed into store into real paying customers. This is where the famous conversion ratio (i.e., the percentage of 
visitors who have stepped into a textile fashion store and have made a purchase) comes into our reckoning.

Of all the potential customers who entered the stores located in the shopping streets of Madrid, Barcelona and Seville, in December 2018, 47.21\%, 42.44\% and 53.23\%, respectively, ended up becoming real paying customers; that is to say, they bought some product or other.

This data is also very important for analyzing the health and attractiveness of a city's overall commercial circuit. Madrid, Barcelona, and Seville are turning more attractive for retailers in Europe, according to the 'Destination Retail' report by the real estate consultant Jones Lang LaSalle [15]. Besides, these cities are among the top 10 most attractive destinations for distribution (logistics) groups.

Table 2. Statistical values for pedestrian traffic and retail customer traffic for Madrid, Barcelona and Seville.

\begin{tabular}{|l|c|}
\hline \multicolumn{1}{|c|}{ City } & Data \\
\hline Madrid & 29,129 \\
\hline Attraction ratio & $9.75 \%$ \\
\hline Daily visitors & 583 \\
\hline Conversion ratio $\quad$ Barcelona & $32.34 \%$ \\
\hline Daily customers & 189 \\
\hline & \\
\hline Daily pedestrians & 25,135 \\
\hline Attraction ratio & $8,97 \%$ \\
\hline Daily visitors & 511 \\
\hline Conversion ratio & $34.42 \%$ \\
\hline Daily customers & 178 \\
\hline & \\
\hline Daily pedestrians & 21.817 \\
\hline Attraction ratio & $7,99 \%$ \\
\hline Daily visitors & 564 \\
\hline Conversion ratio & $33,32 \%$ \\
\hline Daily customers & 134 \\
\hline
\end{tabular}

Source: Own elaboration

At last, in line with our objectives and, importantly, in the light of verifiable data, we understand big data has an increasingly significant role in trade and advertising. Certainly, there is an increase in the number of real shoppers entering stores as evidenced by various KPIs. And, as a consequence, the profitability of a store or any other commercial establishment increases as demonstrated by the cost of marketing $€ / \mathrm{month} / \mathrm{m} 2$, and the location of the store has a huge influence on this outcome success.

\section{Discussion}

First of all, as a result of the developments in the retail intelligence space, retail stores are better placed than ever before to resolve many of their day-to-day concerns in an 
expeditious manner. With the advent of retail intelligence tools, store managers now have a powerful ally and a weapon for good to make important decisions faster and navigate their challenges smoothly. The accurate interpretation of retail data causes new ideas to emerge, and, aided by retail data software, retailers now feel more confident of putting these promising ideas into practice. In the past, store expansion for example, was, for the most part, an arbitrary decision subject to someone's caprice. By contrast, the contemporary retailer's decision-making process has reliable, quantitative, and objective data backing it up. And because these powerful retail intelligence applications allow real-time analysis of reams and reams of critical-to-business data, enterprises have 24/7/365 access to relevant and comprehensive information [16]:

- On internal variables (range, space, prices, promotions, ff, sales)

- On external variables (area of influence and its commercial mix)

- Along different parameters of consumer behavior (pedestrian flows, visitor entries, length of stay, seating capacity, hot spots, etc.).

At the same time, indicators of business results and financial metrics provide general data on the sales and profitability of these commercial spaces. There is also enough room for incentivizing sales by POS staff by way of bonus for meeting and exceeding sales targets, depending on the number of estimated customers and the possibility of selling to them.

By applying the conversion ratio, we can get to know the exact number of potential customers who did not make a final purchase, and based on this data, it is possible to rejig staff at the establishment concerned or rework the marketing mix (products, pricing, communication), bringing into play new permutations and combinations. In addition, as data collection is done in real time, we can extract the time curve of customer arrivals and observe at what time of day and on what days of the week, it is necessary to add more staff and how they can be leveraged most effectively within the budget.

As final considerations of the work, and in light of the results obtained through observation, we can draw several conclusions. So, as we can see, the possibilities for retail intelligence in terms of data analysis are really unlimited (with the exception of the Organic Law on Data Protection (1999) in Spain ${ }^{2}$ ). The recommendation, at any case, is to find out what will be the purpose of obtaining data to optimize decision marketing (included advertising, and the rest variables of communication) and business.

\section{$5 \quad$ Avenues for Further Research}

Increased use of big data generates an entire swathe of new opportunities that there never was, and this is more so in relation to advertising, merchandising, and points of sale activities [17]. Our research attempts to provide a contextualized and theoretically grounded account of the need to leverage big data in order to put a figure on retail consumer behavior that is nearly accurate if not exact. Although our research succeeded

${ }^{2}$ Ley Orgánica 15/1999, de 13 de diciembre, de Protección de Datos de Carácter Personal (LOPD). 
in presenting the processes that link those data with the purchase process in stores, the takeaways for other sectors is a line of investigation that can be further pursued. Even though retail sector serves as a typical example, there are of course other industries where data intelligence can be applied with diverse implications. From a wider perspective, some of the questions we raised spring from the vision of other disciplines like psychology. Therefore, thought leaders and practitioners in those areas should be able to throw more meaningful light on the purchase decisions and the consumer behavior in retail stores, and, by so doing, further enrich the literature on marketing and advertising.

Future research may also strive to investigate the effects on consumer sentiment and decision making of "concrete" advertising collateral, which are perceptible by touch, at the physical points of sale in order to know the effects on consumer sentiment and decision making in more detail.

\section{References}

[1] Instituto Nacional de Estadística. "Informe económico 2019. Infoadex (2019). Resumen Infoadex de la inversión publicitaria en España, 2019". [Online]. Available: https://www. infoadex.es/home/estudio-infoadex-de-la-inversion-publicitaria-en-espana-2019/. [Accessed: March, 16, 2020]. https://doi.org/10.7195/ri14.v12i1.609.s530

[2] M. Fernández Melgarejo. "Retail intelligence” In La gestión profesional del merchandising, G. Jiménez-Marín, Barcelona: UOC, 2017, pp. 47-68.

[3] Interactive Advertising Bureau. Estudio anual de redes sociales, 2016. Interactive Advertising Bureau, Spain, 2018.

[4] S.H. Asenador. "Singles' Day: Alibaba logra superar un año más las ventas del 'Black Friday' y el 'Cyber Monday' juntas", Expansión. 2016. [Online]. Available: http://www.expansion.com/economiadigital/2016/11/12/582752cce5fdea6a0f8b45c6.html. [Accessed: Jan., 17, 2019].

[5] G. Jiménez-Marín, La gestión profesional del merchandising. Barcelona: UOC, 2017.

[6] S. Kalinin, B. Sumpter and R. Archibald. "Big-deep-smart data in imaging for guiding materials design”, Nature Materials, no.14, pp. 973-980, 2015. https://doi.org/10.1038/nmat $\underline{4395}$

[7] V. C. Gungor et al. "Smart Grid Technologies: Communication Technologies and Standards", IEEE Transactions on Industrial Informatics, vol. 7, no. 4, nov., pp. 529-539, 2011.

[8] C. Feijóo-González, J.L. Gómez-Barroso and I. J. Martínez-Martínez. "Nuevas vías para la comunicación empresarial: publicidad en el móvil”, El profesional de la información, vol. 19, no. 2, mar.-abr., pp. 140-148, 2010. https://doi.org/10.3145/epi.2010.mar.04

[9] O. Busch. Programmatic advertising, Berlin: Springer International Publishing, 2016.

[10] L. Kelley, K. Sheehan, K and D.W. Jugenheimer, Advertising media planning: A brand management approach. London: Routledge, 2015. https://doi.org/10.4324/9781315720579

[11] Interactive Advertising Bureau. Programmatic trading. An IAB Europe whitepaper. IAB Europe. [Online]. Available: http://www.iabeurope.eu/files/8614/0776/0957/IAB_Europe Programmatic_Trading_White_Paper_July_2014_v2.pdf, 2014. [Accessed: February, 16, 2020]. https://doi.org/10.4135/9781452229669.n1701 
[12] I.J. Martínez-Martínez, J.M. Aguado and Boeykens, Y. "Implicaciones éticas de la automatización de la publicidad digital: caso de la publicidad programática en España". El profesional de la información, vol. 26, no. 2, mar.-abr., pp. 201-210, 2017. https://doi.org/10. 3145/epi.2010.mar.04

[13] Interactive Advertising Bureau. US programmatic ad revenues totaled \$10.1 billion in 2014, according to first-ever IAB programmatic revenue report. [Online]. Available: https://www.iab.com/news/u-s-programmatic-display-adrevenues-totaled-10-1-billion-in2014-according-to-first-everiab-programmatic-revenue-report, 2015. [Accessed: March, 02, 2020]. https://doi.org/10.1007/978-3-319-25023-6_4

[14] M. J. González. Metodología de la investigación social. Técnicas de recolección de datos. Alicante: Aguaclara, 1997.

[15] TC Group Solutions. "Informe Big Data sobre el Comportamiento del Consumidor". TC Group Solutions, 2018.

[16] Coelho, P., Correia, P., \& Garcia Medina, I., (2017). Social Media: A New Way of Public and Political Communication in Digital Media. International Journal of Interactive Mobile Technologies (iJIM). ISSN: 1865-7923. Vol 11, No 6, 150-157. https://doi.org/10.3991/ ijim.v11i6.6876.

[17] Correia, P. \& Garcia Medina, I., (2014). Digital Social Media: An Interactive Technology Incorporated as a Competitive Advantage for Business. International Journal of Interactive Mobile Technologies (iJIM). ISSN: 1865-7923. V. 8, (2), 31-35; https://doi.org/10. 3991/ijim.v8i2.3576.

[18] Correia, P. \& Garcia Medina, I., (2012). The Importance of Social Media for Commerce. A Case Study in Madeira (Portugal). International Journal of Interactive Mobile Technologies (iJIM). ISSN: 2177-6288. V. 6, (1), 208-222; https://doi.org/10.3991/ijim.v6i1.1825.

\section{$7 \quad$ Authors}

Dr. Gloria Jiménez-Marín has a Ph.D. from the University of Seville and graduate in Advertising and Public Relations and in Journalism by the same university. Currently, she is a lecturer at the Audio-visual Communication and Advertising Department of the University of Seville. Previously, she was a lecturer at the Business Management and Marketing Department of the University of Huelva, the Marketing and Communication Department of the University of Cadiz, the Business Organization and Marketing of the University School of Osuna (part of the University of Seville), and the Universitat Oberta de Catalunya. At an academic level, Jiménez-Marín has published several texts related to the design of commercial spaces, merchandising, retail and commercial distribution, as well as she has taken part in a series of collective books on advertising. Besides, Jiménez-Marín has published papers in advertising journals as Global Media Journal, Comunicar, Questiones Publicitarias, Trípodos, Comunicación, Ámbitos o Zer. From a professional perspective, she has worked in several media-radio and press-, in advertising agencies and in communication departments of various organizations before she began in teaching and researching Universities. gloriajimenez@us.es

Dr. Paloma Sanz-Marcos holds a Ph.D in Communication (international mention by UC Berkeley, California) and a degree in Advertising and Public Relations. She is lecturer at the Department of Audiovisual Communication and Advertising of the University of Seville. She Currently she combines her work as a researcher and lecturer 
with the participation in congresses, publication of articles in scientific journals and teaching subjects related to branding, sports and popular culture. She has published in journals such as Journal of Consumer culture, Journal of Communication Management or Journal of Popular culture. She has been collaborated with institutions such as UC Berkeley or Pontificia Universidad Católica de Chile. palomasanz@us.es

Dr. Irene García Medina is a lecturer in Marketing at the Glasgow Caledonian University (Glasgow, United Kingdom). She is bachelor of Communication Sciences (Complutense University of Madrid, Spain) and Ph.D. in Marketing (University of Sophia - Antipolis, France) and International Relations (University of Vienna, Austria). As a teacher, García Medina has previously taught Marketing and International Business Management at graduate level and master's degree in the Faculty of Business and Economics at the University of Madeira (Portugal), at the University of Vic (Spain) and at the University Pompeu Fabra (Spain). As a professional, she has worked, among others, as Marketing Director of the French company VTDIM, as Consultant for the Portuguese Chamber of Commerce, as Head of Communication and Promotion of CORDIS (European Commission, DGXIII, and Luxembourg). She has given lectures, seminars and workshops in the field of marketing and advertising in several countries and has published numerous articles and books. Her main areas of interest in research are mobile marketing, digital marketing, digital communication, social media and ebranding. irene.garcia2@gcu.ac.uk

Dr. Patrícia Margarida Farias Coelho has a $\mathrm{PhD}$ in Communication and Semiotics from the Pontifical Catholic University of São Paulo (2010). Post-Doctorate by (i) PostGraduate Program in Intelligence Technologies and Digital Design at PUC-SP with FAPESP scholarship, (ii) Post-Doctorate in Digital Communication by the University of Murcia, (iii) Post-Doctorate in Communication Digital by Universitat Autonoma de Barcelona, (iv) Postdoctoral in the Education and Curriculum Program and (v) Currently doing Postdoctoral in Communication and Consumption at the University of Seville. She worked as a visiting professor at the Pompeu Fabra University in Barcelona - Spain and at the Universitat de VIC / Spain from 2012 to 2014. She is currently a permanent professor in the Masters and Doctorate Program in Education at the Methodist University of São Paulo (UMESP since 2018) and a permanent professor (20 hours) since 2019 in the Master's Program in Education, Subjectivity and Psychoanalysis at Ibirapuera University (UNIB). She was a full professor in the Interdisciplinary Master in Human Sciences at the University Santo Amaro (UNISA) and coordinator of International Relations at the same institution (2016 - 2018) and collaborating professor in the Professional Master Course in "Education and New Technologies" at UNINTER since 2016-2017. Permanent Visiting Professor at the University of Santander - Colombia and in the Graduate Program at the University of Guadalajarra. Member of the Contemporary Academy of Letters chair number 28 whose patron is Monteiro Lobato. She currently has a Research Project entitled "Teacher Training and Digital Technologies Applied to Education" funded by Fapesp. She is the coordinator of Lato Sensu Courses at the Methodist University of São Paulo: Special and Inclusive Education and Management in Education: Direction and Coordination. patriciafariascoelho@gmail.com

Article submitted 2020-03-23. Resubmitted 2020-04-20. Final acceptance 2020-04-20. Final version published as submitted by the authors. 